\title{
S \\ 2 \\ Memoria del Primer Congreso del Área Cultural Ulúa Matagalpa
}

\author{
Fundación Científica Ulúa-Matagalpa (Matagalpa, 2016) \\ N. 301 ISBN 978-99964-935-0-8. 360 páginas.
}

Por Mario Rizo ${ }^{1}$

El libro que presentamos es el resultado de un congreso internacional convocado y llevado a cabo en la ciudad de Matagalpa en el verano del año 2014. La propuesta de un área cultural con la denominación "Ulúa-Matagalpa" ha tenido desde entonces una creciente acogida por la comunidad científica. El evento contó con la participación de investigadores e investigadoras de Nicaragua, Honduras, El Salvador, Costa Rica, Estados Unidos, Canadá, Holanda, Francia, Noruega, Alemania e Italia, con participación de estudiantes de 11 universidades nacionales y centroamericanas, líderes indígenas, alcaldes, periodistas y maestros, sumándose en el congreso un total de 180 participantes.

La Memoria recoge las actas de las 18 ponencias presentadas por 26 investigadores que representan la ralea de la comunidad científica nacional e internacional que labora en dicha área cultural. El Dr. John Henderson, de la Universidad de Cornel, en Nueva York, y uno de los más prominentes mayistas, ha dicho recientemente del libro:

La importancia del Congreso del área cultural gran Ulúa-Matagalpa, no puede ser exagerada. Entender las regiones surorientales de Mesoamérica como área cultural que contiene tradiciones localizadas pero relacionadas, mejorará en gran medida la comprensión arqueológica de la riqueza del pasado. En términos metodológicos tenemos la oportunidad de desarrollar una arqueología transnacional, en que los investigadores usan las mismas categorías y conceptos equivalentes $y$ tal vez se interesen en los mismos asuntos.

El arquitecto Luis Morales, codirector del Instituto Nicaragüense de Cultura se ha expresado de la Memoria en términos que elogian el esfuerzo científico desarrollado y que marca una diferencia entre el "ayer de la arqueología" y el presente. El Congreso permitió avistar un capital de información cultural de la historia antigua de Nicaragua, con un registro de datos arqueológicos, históricos, lingüísticos y etnográficos comunes en el área, evidenciando su parentesco con culturas vecinas como el área maya en el sur de Mesoamérica, la zona chibcha del sur o área Intermedia, con el área de gran Nicoya, en el pacífico sur de Nicaragua y norte de Costa Rica, hundiéndose en el tiempo antiguo hasta épocas remotas de la arqueología.

El libro ha sido publicado por la Fundación Científica Cultural Ulúa Matagalpa, bajo el cuido editorial de los arqueólogos Rigoberto Navarro y Paul Cruz y del antropólogo Mario Rizo, investigadores y directivos del congreso y la Fundación.

1 Maestro en Antropología y Etnohistoriador, Abogado y Notario, Secretario e Investigador en la Fundación Científica Cultural Ulúa-Matagalpa. 